\title{
An overview of prognostic factors for long-term survivors of breast cancer
}

\author{
Isabelle Soerjomataram • Marieke W. J. Louwman • \\ Jacques G. Ribot · Jan A. Roukema • \\ Jan Willem W. Coebergh
}

Received: 16 February 2007/ Accepted: 20 February 2007/Published online: 22 March 2007

(C) Springer Science+Business Media B.V. 2007

\begin{abstract}
Background Numerous studies have examined prognostic factors for survival of breast cancer patients, but relatively few have dealt specifically with 10+-year survivors.

Methods A review of the PubMed database from 1995 to 2006 was undertaken with the following inclusion criteria: median/mean follow-up time at least 10 years; overall survival and/or disease-specific survival known; and relative risk and statistical probability values reported. In addition, we used data from the long-standing Eindhoven Cancer Registry to illustrate survival probability as indicated by various prognostic factors.

Results 10-year breast cancer survivors showed 90\% 5year relative survival. Tumor size, nodal status and grade remained the most important prognostic factors for longterm survival, although their role decreased over time. Most studies agreed on the long-term prognostic values of MI (mitotic index), LVI (lymphovascular invasion), Her2positivity, gene profiling and comorbidity for either all or a
\end{abstract}

I. Soerjomataram $(\bowtie) \cdot$ J. W. W. Coebergh

Department of Public Health, Erasmus MC, P.O. Box 2040,

Rotterdam 3000 CA, The Netherlands

e-mail: i.soerjomataram@erasmusmc.nl

I. Soerjomataram · M. W. J. Louwman .

J. W. W. Coebergh

Comprehensive Cancer Centre South, P.O. Box 231, 5600 AE

Eindhoven, The Netherlands

J. G. Ribot

Department of Radiotherapy Catharina Hospital, P.O. Box 1350,

5602 ZA Eindhoven, The Netherlands

J. A. Roukema

Department of Surgery, St. Elisabeth Hospital, P.O. Box 90151,

5000 LC Tilburg, The Netherlands subgroup of breast cancer patients (node-positive or negative). The roles of age, socioeconomic status, histological type, BRCA and p53 mutation were mixed, often decreasing after correction for stronger prognosticators, thus limiting their clinical value. Local and regional recurrence, metastases and second cancer may substantially impair long-term survival. Healthy lifestyle was consistently related to lower overall mortality.

Conclusions Effects of traditional prognostic factors persist in the long term and more recent factors need further follow-up. The prognosis for breast cancer patients who have survived at least 10 years is favourable and increases over time. Improved long-term survival can be achieved by earlier detection, more effective modern therapy and healthier lifestyle.

Keywords Breast cancer - Long-term ·

Prognostic factors · Survival

\section{Introduction}

Breast cancer (BC) is the most common cancer among women, with a lifetime risk of up to $12 \%$ and a risk of death of up to $5 \%$ [1]. Its incidence has been increasing but after a period of continuous rise in many industrialized countries BC mortality has been stable or has even decreased in the last 10-15 years [2, 3]. The introduction of mass mammographic screening programmes also resulted in earlier detection and diagnosis of small and less aggressive tumours. This, in combination with therapeutic improvements, has led to a substantial increase in BC survivors over the last few decades (Fig. 1). A long-term survivor is commonly defined as a person who is still alive 5 years after cancer diagnosis [4]. For BC, the relative 


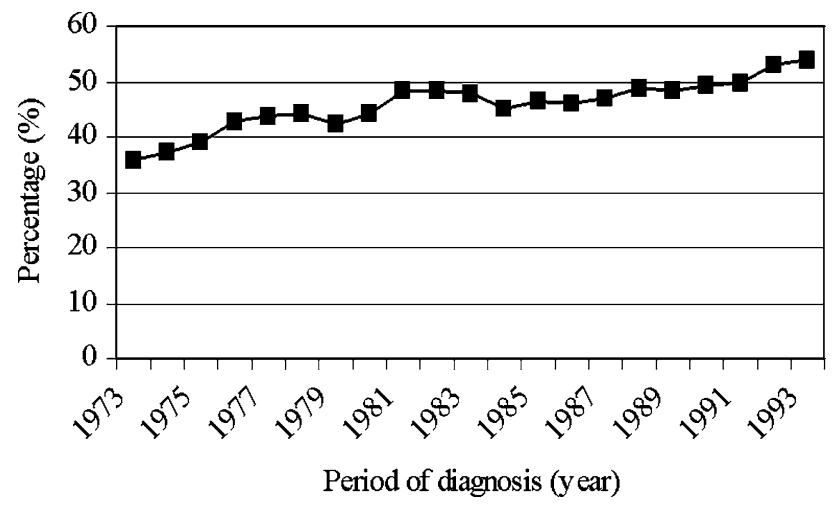

Fig. 1 Proportion of breast cancer patients (3-year moving average) diagnosed between 1973 and 1993 who survived 10 years or longer in Southeastern Netherlands

survival at 5 and 10 years after diagnosis is $88 \%$ and $77 \%$, respectively, both substantially higher than the 5-year relative survival of all cancers together (64\%) [4]. Thus, it seems logical to consider factors known to play an important role in predicting 5-year survival of BC patients and to question their importance in survival 10 years after diagnosis and even longer. Furthermore, in recent years major advances in the prognostic value of several molecular markers have been achieved, hence the need to incorporate this data into our current knowledge. Therefore, we have summarized available knowledge on the determinants of survival 10 years or more after breast cancer diagnosis. We supported our analyses and considerations with data from the population-based, long-standing Eindhoven cancer registry in the Netherlands.

\section{Methods}

We initially searched PubMed, using the search MESH term for 'breast neoplasms' AND 'prognoses' AND 'longterm'. Only papers published in English between 1995 and 2006 (September) which researched female adults (19+ years) were included. We retrieved 528 articles and studied the abstracts (sometimes also the methods section). We selected only articles that assess or show the results for those surviving 10 years or longer with cohorts having a mean/median follow-up of 10 years or longer. If mean/ median follow-up time was not reported, we examined the proportion of patients who survived 10 years after diagnosis, and this ought to be larger than $50 \%$. If, for a specific topic of interest, no relevant studies with a follow-up of at least 10 years were found (such as BRCA mutation or gene profiling, which have been studied only during the last decade), then studies with the longest available follow-up were chosen. Furthermore, the following inclusion criteria were used: overall and/or BC-specific survival was reported; relative risk or hazard rate and statistical probability values were given; at least $250 \mathrm{BC}$ patients included at the beginning of study. We also searched the reference lists collected by this search strategy and selected those that were relevant to both our study question and inclusion criteria. Reviews and books that gave general overviews were also included in the reference list.

We present data from the Eindhoven Cancer Registry (ECR) to illustrate the role of factors such as age, tumour size, lymph node involvement and time since diagnosis. Within the Netherlands, ECR is unique because it has collected follow-up data since 1970, including clinical aspects of cancer patients. This is a population-based cancer registry covering a population of almost 2.4 million people in 2004 [5]. Cumulative survival proportion was calculated using the Kaplan Meier method. Relative survival was calculated by comparing the survival of $\mathrm{BC}$ patients to the general population.

Throughout the text the term long-term and/or survival will frequently be mentioned; this corresponds to at least 10-year survival unless otherwise indicated.

\section{Results and discussions}

Determinants of survival BC 10 years or longer

\section{Patient characteristics}

Age at diagnosis Very young women, i.e. younger than $30 / 35$ years $[6,7]$, exhibited a particularly poor survival as do those older than 70 (Fig. 2) [8,9]. Young BC patients were more likely to have a more negative clinical presentation, such as affected lymph nodes, negative for oestrogen receptors, and have large tumour with a high fraction of p53 nuclei and overexpression of c-erb-2 oncoprotein [6, 10, 11]. However, current adjuvant treatment seems to diminish the poor prognostic value of young age [6]; young women who did not receive adjuvant treatment had a significantly increased risk of dying; those diagnosed at 35-39 years and $<35$ years had a 1.4 and 2.2 higher risk of death, respectively, compared to those of 45-49 years [6]. Older patients exhibited higher mortality rates [12], probably because of less extensive treatment (either related to advanced age itself or the presence of serious concomitant diseases (comorbidity)) [13].

Comorbidity Concurrent health conditions (comorbidity) at the time of $\mathrm{BC}$ diagnosis have a significant impact on early [13] as well as long-term survival of BC patients [12]. The most prevalent conditions were cardiovascular disease (7\%), previous cancer (7\%) and diabetes mellitus (6\%), all 


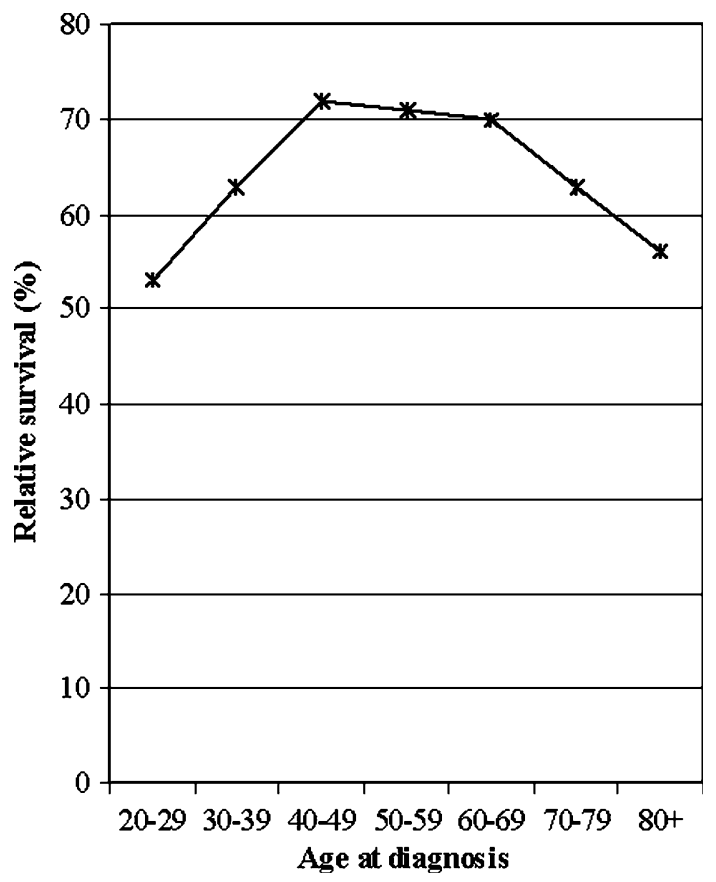

Fig. 2 Relative survival of breast cancer patients (n: 13,279) diagnosed in 1990-2002 and followed until 2004, according to age at diagnosis in southeastern Netherlands

becoming more common with increasing age [13]. Compared to those without comorbidity whose 5-year relative survival was $87 \%$, those with diabetes mellitus or cardiovascular disease represented $78 \%$ and $83 \%$ of the respective survival estimates [13]. Patients with severe comorbidity exhibited a 2.7-3.4 higher risk of death in 10 years compared to those without comorbidity $[12,14]$.

Period of diagnosis Access to care and treatment of $\mathrm{BC}$ has improved over time in most industrialized countries, which is reflected in the higher long-term survival of $\mathrm{BC}$ cases across all age groups and the tumour characteristics of those diagnosed more recently [15-18]. In Finland, relative survival 10 years after diagnosis among patients younger than 50 years increased from $49 \%$ for those diagnosed in 1953-1959 to 68\% for the 1983-1989 cohort [15]. Furthermore, $60 \%$ of node-positive BC patients diagnosed in 1978-1979 in Italy survived 10 years or longer compared to the $50 \%$ probability 10 -year survival for those diagnosed in 1968-1969 [17]. In addition, changes in BC diagnosis, e.g. screening[19, 20] and better staging [17], may partly be responsible for the observed increase in the proportion of survivors.

Time after diagnosis The longer a woman survives $\mathrm{BC}$ the more the prognosis improves, illustrated by conditional survival $[16,21]$. Probably the subgroup of patients who

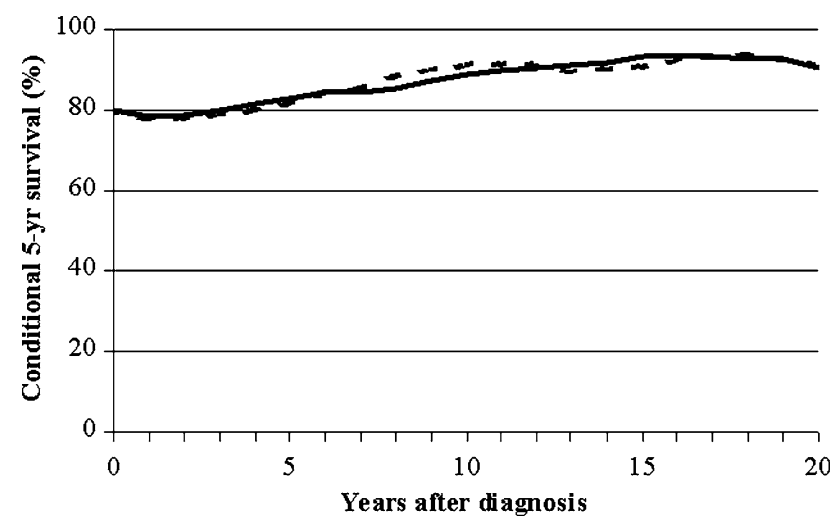

Fig. 3 Conditional 5-year relative survival (calculated using period analysis [22] of breast cancer patients diagnosed in southern Netherlands in 1985-2002 and followed until 2004, according to age. (Dashed line): diagnosed at 25-49 years, (solid line): diagnosed at $50-74$ years

survived longer had less aggressive tumours due to a different genetic make-up or better life-style. In Australia, $79 \%$ of women with localized BC survived 10 years after diagnosis, yet among those still alive 5 years after diagnosis $84 \%$ had a 10 -year survival [16]. The respective values for regional vs. advanced $\mathrm{BC}$ were $53 \%$ and $68 \%$ [16]. Unlike other cancers, relative conditional survival remained stable below $100 \%$ after 12 years of survival and decreased again after about 19 years (Fig. 3) [5]. This may be a consequence of late recurrences and metastases, second cancers or late side-effects of treatment [23].

Socioeconomic status (SES) and race A population-based study of BC patients diagnosed in 1968-1999 in France showed a diminishing role of SES on excess mortality among women with $\mathrm{BC}$ over these periods [24]. Long-term follow-up studies reported that women with $\mathrm{BC}$ from low social classes had a $20-50 \%$ poorer survival compared to patients from higher social classes [25, 26], although others contradicted this [27]. Low SES patients were more likely to be diagnosed at a later stage, had more aggressive tumour characteristics and might have received sub-optimal treatment. However, differences in these prognostic factors did not fully explain the variation in survival according to social class [25]. This is also the case when breast cancer survival is studied according to race/ethnicity. Ten years after treatment 58\% of African Americans were still alive compared to $66 \%$ of the white Americans. After adjusting for other prognostic factors, $41 \%$ excess mortality from all causes was still observed among African Americans compared to caucasians [28]. This suggests other residual factors such as lifestyle (higher body weight was observed among African Americans), comorbidity [14], genetics or variation in the delivery of treatment, which influence outcome beyond variation in tumour aggressiveness [29]. 


\section{Tumour-related characteristics}

Tumour size Tumour size is one of the strongest prognostic indicators (Fig. 4) [7, 30], even after 20 years of follow-up [8, 31]. A larger tumour has been related to more positive lymph nodes [32], thus their interaction further influences the survival from BC. Nonetheless, the independence of survival by node status is shown by the lower 10-year overall survival rate found for node-negative patients with a tumour of 2-5 cm compared to those with a tumour smaller than $1 \mathrm{~cm}, 66 \%$ vs. $79 \%$, respectively [33].

Histological type The prognostic value of histological type can be grouped into four: excellent, good, poor and very poor prognosis [34]. BC with an excellent prognosis, such as invasive cribriform, tubular [35], tubulo-lobular and mucinous $[36,37]$ showed $>80 \%$ survival at 10 years [9]. Tubular mixed, mixed ductal with special type, atypical medullary [38] and alveolar lobular carcinoma have a good prognosis with a 60-80\% 10-year survival. Those with invasive papillary, classic lobular and medullary cancers have a worse prognosis. Finally, 10-year survival among those with ductal, solid lobular, mixed ductal and lobular carcinoma is below $50 \%$ [34]. In most populations infiltrating ductal carcinoma covers about $70 \%$ of all diagnoses [36, 39]. Inflammatory $\mathrm{BC}$ has a particularly poor prognosis: about $30 \%$ survived 10 years [40].

Histological grade The most widely used grading systems are Scarff-Bloom-Richardson classification, Fisher grading nuclear system and Nottingham Combined Histologic Grade (NCHG) [41]. The validity of grading has been subjected to inter-observer reproducibility and subjectivity

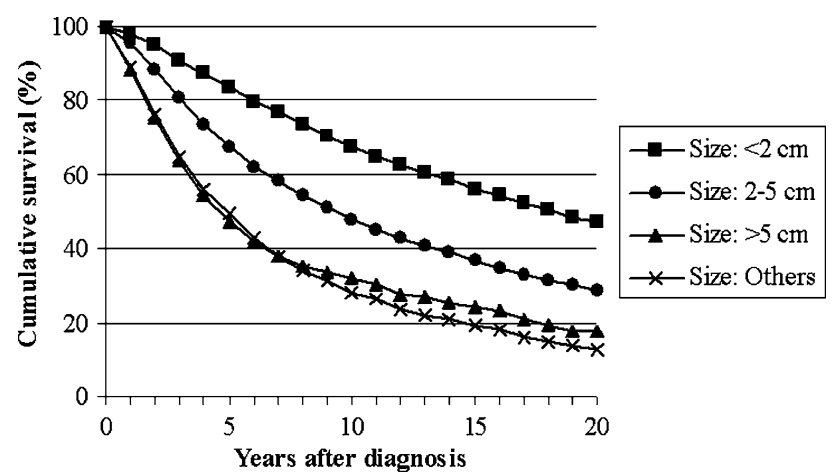

Fig. 4 Cumulative survival proportion of breast cancer patients diagnosed in southern Netherlands in 1970-1994 and followed until 2004, according to tumor size (based on pathological diagnosis). tumor size: $<2 \mathrm{~cm}(\mathrm{n}: 3263) \bullet$ tumor size: $2-5 \mathrm{~cm}$ (n: 3420$) \boldsymbol{\Delta}$ tumor size: $>5 \mathrm{~cm}$ (n: 474$) \mathbf{x}$ tumor size: involvement of skin (n: 1133) and unknown/not applicable tumor size: 1410
[42]. However, higher grades have been quite consistently associated with lower long-term survival [7, 8, 31, 43-45]. Depending on other prognostic factors, such as nodal status or tumour size [46, 47], cumulative survival among patients with the lowest score was 90-94\% 10 years after diagnosis and 30-78\% among those with the highest score $[37,48]$.

Regional lymph node involvement Lymph node involvement is a valuable indicator of long-term survival (Fig. 5) [8, 32]. Node- positive patients have about a 4-8 times higher mortality than those without nodal involvement [8, 9, 49]. The more nodes involved the worse the prognosis. Prognosis for patients with 10 or more involved axillary nodes showed $70 \%$ more deaths at 10 years than for those with 1-3 involved nodes [32]. The survival of node-positive patients improved due to better staging procedures and application of systemic treatment [7, 31, 50].

Lymphovascular invasion (LVI) and molecular markers of tumours angiogenesis At the St. Gallen meeting in 2005, LVI was added to the prognostics for node-negative patients [51]. Compared to patients having no LVI, a $60 \%$ higher BC mortality was observed for node-negative BC patients having positive LVI [52, 53], although others did not observe the independent role of LVI [46, 50]. In this line of research, studies have also focused on the value of microvessel density [44], blood invasion (BVI) [54] and markers of angiogenesis (VEGFR (vascular endothelial growth factor receptor), CD105, Tie-2) [55, 56] in predicting long-term survival of $\mathrm{BC}$ patients, although the results are still conflicting.

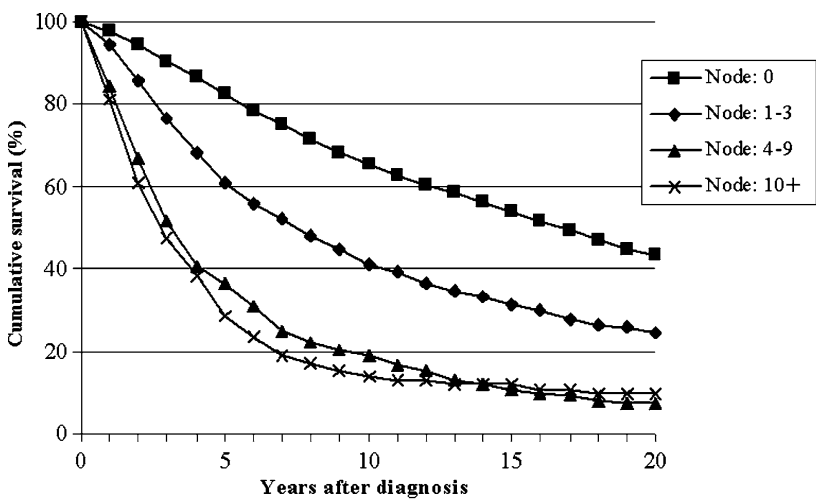

Fig. 5 Cumulative survival proportion of breast cancer patients diagnosed in southern Netherlands in 1970-1994 and followed until 2004, according to nodal status (based on pathological diagnosis). node negative (n: 4452) $\bullet$ node status: $1-3$ positive nodes (n: 3266$) \boldsymbol{\Delta}$ node status: 4-9 positive nodes (n: 255$) \mathbf{x}$ node status: $10+$ positive nodes (n: 189), unknown/not applicable node status: 1538 
Grouped prognostic factors Some of the prognostic factors have been combined into a prognostic index, such as the TNM classification and also the more current Nottingham Prognostic Index (NPI), both highly predictive for estimating long-term survival [41]. TNM staging consists of information on primary tumour size, involvement of the regional lymph node and the presence of distant metastasis. Only $53 \%$ of patients with regional or locally advanced BC had survived 10 years after diagnosis compared to $79 \%$ of those with localised BC [16]. Patients with metastasis (stage: M1) at diagnosis exhibited very poor 10-year survival $(3.4 \%)$ [57].

Tumour size, grade and lymph node status make up the NPI [11, 46, 49]. In a large series of 2879 BC patients, 10 -year survival proportion was $85 \%$ for those with the lowest NPI score and $19 \%$ for those with the highest score [11].

\section{Recurrence, metastasis and second cancer}

Patients with recurrent, metastasized or second cancer generally exhibited lower long-term survival than those without [9, 21, 58-61]. Ten years after surgery, the probability for survival for another 10 years, thus 20 years after diagnosis, for node-negative patients aged $\geq 45$ years, tumour $\leq 1 \mathrm{~cm}$, grade 1 and without a recurrence or metastasis was 0.89 . If a recurrence occurred, the probability of being alive at 20 years dropped to 0.72 . If a metastasis was observed the probability of survival was only 0.18 [21]. The prognosis decreases with larger primary tumour size, nodal involvement [62], higher grade,[21] early recurrence (within 5 years of surgery)[63], location of recurrence (regional rather than local ipsilateral) [59] and inadequate primary cancer treatment $[9,64]$. In the dataset of the ECR, overall survival was better for women without second primary tumours than for women who developed a new primary cancer (Fig. 6). Only 68\% of early BC patients with second malignancies had survived 10 years of follow-

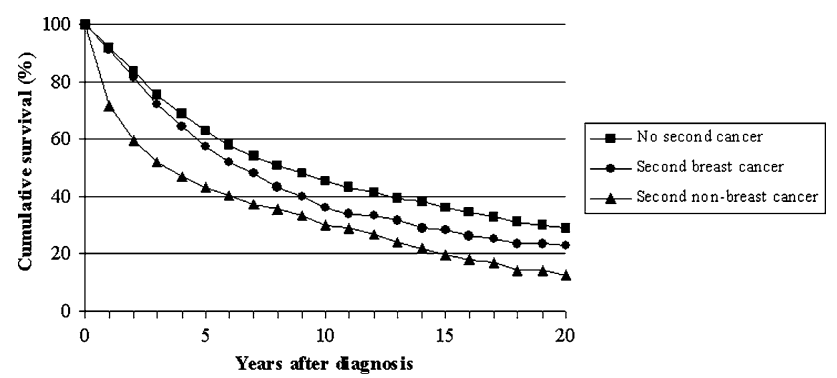

Fig. 6 Cumulative survival of breast cancer patients diagnosed in southern Netherlands in 1970-1994 and followed-up until 2004, according to second cancer. Follow-up for patients with second cancer begins at the date of second cancer diagnosis. no second cancer (n: 8137) • second breast cancer (n: 744) $\boldsymbol{\Delta}$ second non-breast cancer (n: 819) up compared to $78 \%$ of those without multiple cancers [65]. Younger BC patients are reported to have poorer survival and a higher risk of second cancer [59]. Corrected for race and grade, women in the 20-29 year old category who had a second BC had a probability of 10-year survival probability of only $23 \%$ compared to $57 \%$ for those without multiple cancers.

\section{Other tumour markers}

Hormone receptors The presence of hormone receptors such as oestrogen (ER) and progesterone (PR) receptors predicts the long-term outcome of hormonal therapy [66], thus they have been more commonly used as a predictive marker rather than as a prognostic marker. Thus given a particular treatment, e.g. tamoxifen, ER-positive patients have a considerably better prognosis than ER-negative patients. The prognostic value is weak [30, 43] or negligible [37], particularly in the early years after diagnosis [67].

HER-2 expression Node-positive patients with BC cells showing amplification of the gene for human epidermal growth factor receptor type 2 (HER2), and/or overexpression of its product had a lower 10-year overall survival proportion, $50 \%$ versus $65 \%$ for those without HER2 amplification [17, 68]. After 10 years the difference in survival persisted, although it became somewhat smaller[17]. Tumours that overexpress HER2 are more likely to contain p53 abnormalities, to be hormone receptor- and bcl-2-negative and to have lymphoid infiltration and a high mitotic index, all known to be markers of poor prognosis for BC [17, 69, 70]. As for patients with node- negative tumours, HER2 did not seem to affect long-term survival significantly [17, 37, 69]. HER-2 expression has been valuable in predicting treatment responses to trastuzumab, certain endocrine therapies and chemotherapy, adding to it's role as a predictive marker [68].

Mitotic Activity Index (MAI) MAI is an indicator of tumour proliferative activity that represents the mitotic activity in a given area of the tumour. Combined with another prognostic factor (NCHG), MAI has proven to be an accurate tool for assessment of long-term survival [48]. In a population-based study women with node-negative tumours $<5 \mathrm{~cm}$ and a MAI $\geq 10$ exhibited $80 \%$ survival at 10 years compared to $90 \%$ for an MAI $<10$ [71].

Gene expression profile A very promising new finding is the microarrays method, in which a set of intrinsic genes is 
clustered and segregated into major subgroups; $\mathrm{BC}$ with a good and poor prognosis profile is correlated to the probability of distant metastases [72] or a tumour with basal or luminal characteristics which are strongly associated with ER status [73]. In a study of 295 patients diagnosed with stage I or II breast cancer, those classified as having a good prognosis profile had a $95 \%$ overall 10 -year survival rate compared to $55 \%$ for those with a poor profile [74]. This classification predicted outcome regardless of the nodal status, implying that more accurate criteria have become available for administering adjuvant systemic treatment.

Various molecular markers BRCA1 \& 2 mutations were first identified in 1994 and are BC risk factors for some specific groups [75]. Their role as prognostic indicator for long-term (more than 10-year) survival has not yet been established. A study of 496 women (median follow-up: 116 months), 56 of whom (11\%) carried a BRCA1/BRCA2 mutation, showed worse BC-specific survival for women with BRCA1 mutations than for those without $(62 \%$ at 10 years versus $86 \% ; P<0.0001$ ), but not for women with the BRCA2 mutation [76]. However, another study which compared patients from BRCA1, BRCA2 and nonBRCA1/2 families as well as sporadic cases did not confirm the prognostic role of BRCA1/2 [77].

Long-term follow-up studies have not demonstrated an independent effect of p53 mutations on long-term survival. The P53 mutation was related to a poor clinical profile for patients, hence in multivariate analysis its role on survival diminished [10, 69, 78, 79].

A high level of tissue urokinase-type plasminogen activator (uPA) and its inhibitors has been correlated with poor outcome for node-negative and node-positive patients. Those having the highest level of uPA have a five times greater risk of dying from BC compared to those with the lowest level [69]. Other factors such as Ki67 (MIB-1), cathepsin-D, DNA ploidy and S-phase have been suggested as prognosticators of survival, with conflicting results, particularly among long-term survivors. Their use in general clinical settings is therefore not recommended $[80,81]$.

\section{Miscellaneous}

Lifestyle Generally, increased death rates due to $\mathrm{BC}$ (13-20\%), other causes (49-86\%) and all causes (14-70\%) have been observed among obese patients [82-85]. Normal body weight tended be more beneficial in death from other causes than from BC: [83, 84] $9.5 \%$ of obese patients died from non-BC causes compared to $6.4 \%$ and $5.8 \%$, respectively, of the normal or intermediate groups [82]. Obesity was also related to a 2-fold increased risk of postmenopausal contralateral $\mathrm{BC}$ and a
$60 \%$ higher occurrence of second other cancers [84]. Therefore, normal weight may reduce the risk of second post-menopausal BC, second other cancers and overall mortality [83, 84, 86].

Compared with women who engaged in less than 9 metabolic equivalent task (MET)-hours per week of activity, women who engaged in 9 or more MET-hours per week had a $40 \%$ lower risk of death from all causes, translating into a $6 \%$ absolute (unadjusted) reduction in mortality [87], which emphasizes the need to advise physical activity.

So far, although studies have not convincingly shown the positive influence of eating fruit, vegetables and soy bean on long-term BC survival $[85,88]$, diets high in fruits, vegetables, legumes, poultry, and fish and a low intake of red meat, desserts and high fat dairy products are likely to protect against mortality from non-BC causes [89].

\section{Modification of BC's prognostic factors}

Various studies have questioned the role of $\mathrm{BC}$ risk factors in determining the biological tumour features as mentioned above. Indeed, BC risk factors seem to differ according to histological type, grade, size, nodal status and ER/PR receptor status [90-93]. For example, excessive alcohol intake and obesity increased the risk for the development of ER-positive tumours [92, 93]. As for late age at first fullterm birth and obesity are related to an increased risk of large tumours [91]. Hence, risk factors for BC may also affect breast biology and clinical behaviour, thus also BC prognosis.

Changing importance of prognostic factors over time after diagnosis

Commonly, the value of prognostic factors decreases depending on the length of the follow-up period [31, 94]. Survival curves according to prognostic factors usually show a large drop in survival for all stages during the first 5 years; afterwards the curve stabilizes. Studies agreed on the long-lasting influence of tumour size at diagnosis on survival, albeit attenuating over time [31, 94, 95]. Grade, nodal status and metastases were also valuable in predicting survival up to 20 years after diagnosis [31, 95]. Although, others have reported that 10 years after diagnosis only tumour size [94] or nodal status [8] or old age [8] remained as an independent predictor of long-term survival. Similarly, ER/PR status and MAI only had a significant prognostic role in the first 5-10 years after diagnosis [67, 71, 96]. Because even 10 years after BC diagnosis the probability of survival for BC patients does not seem to reach that of the general population, the role of 


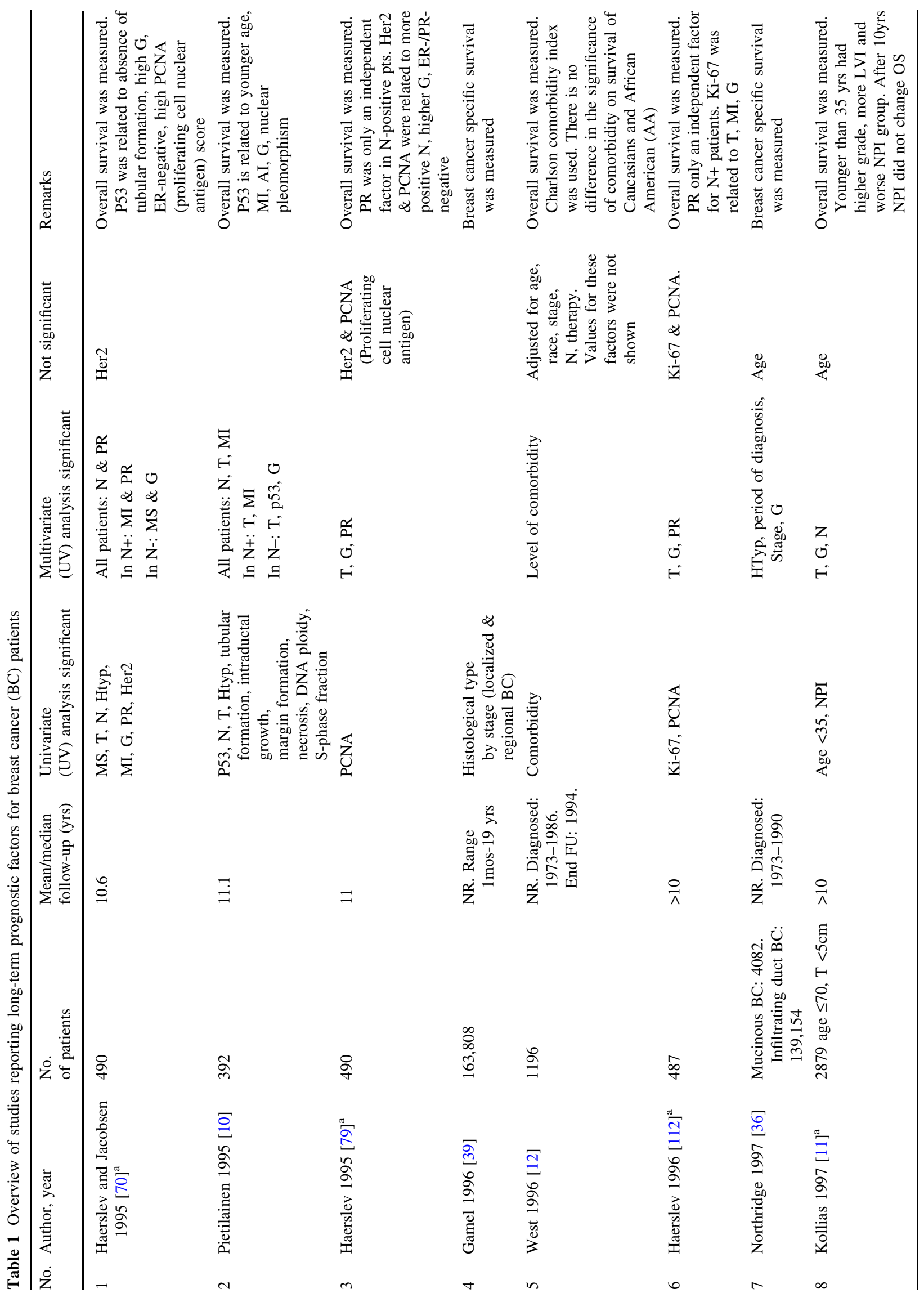




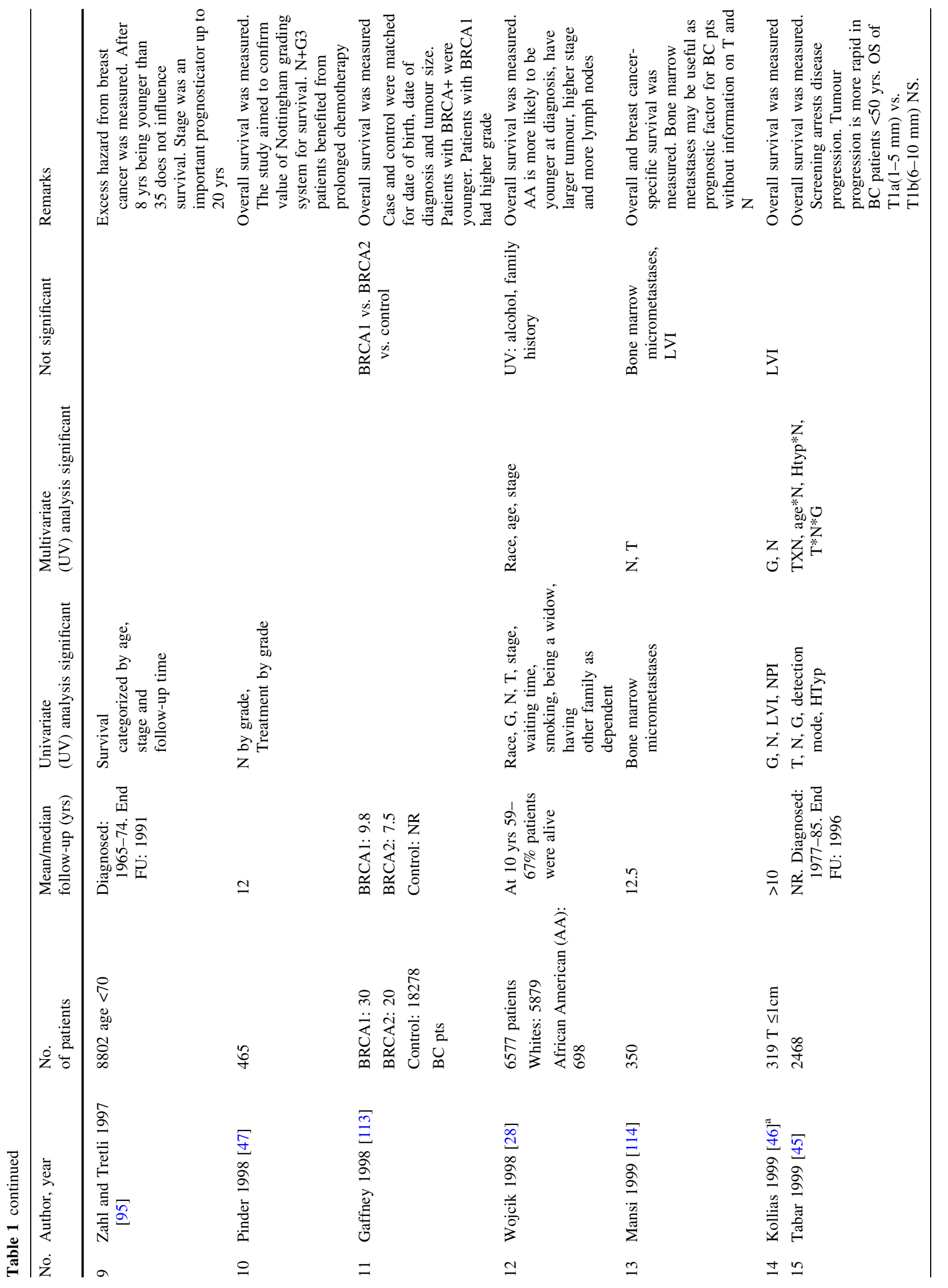




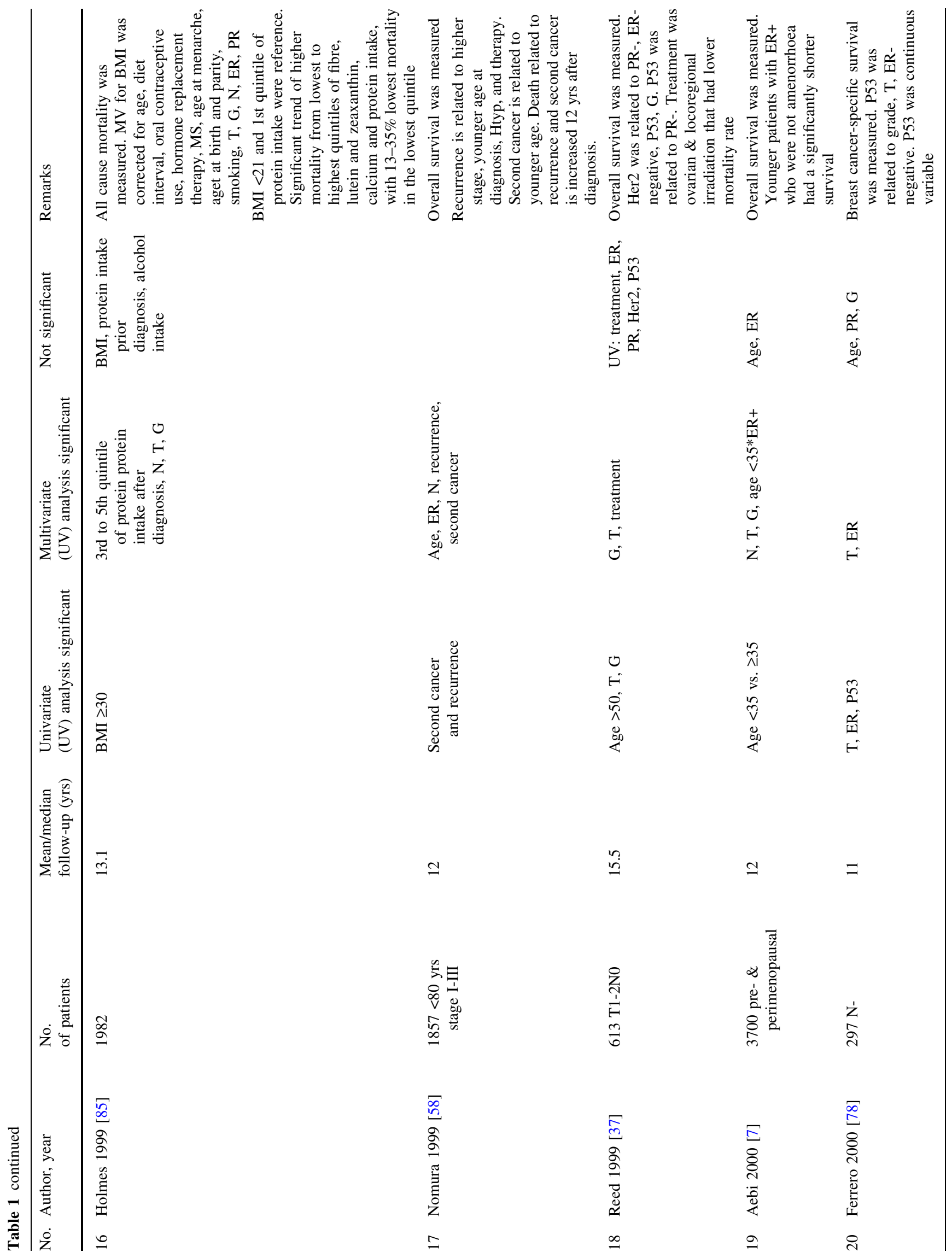




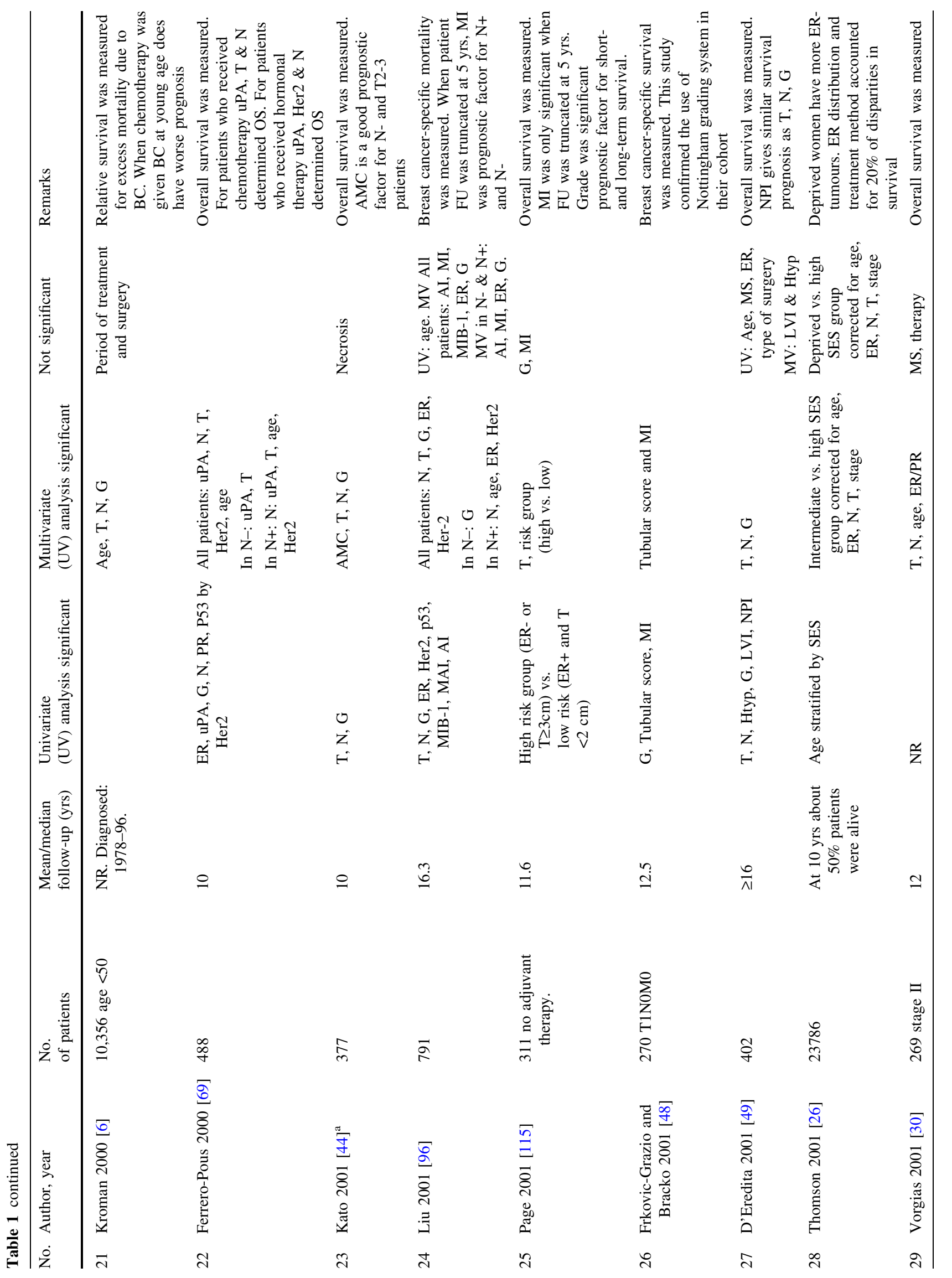




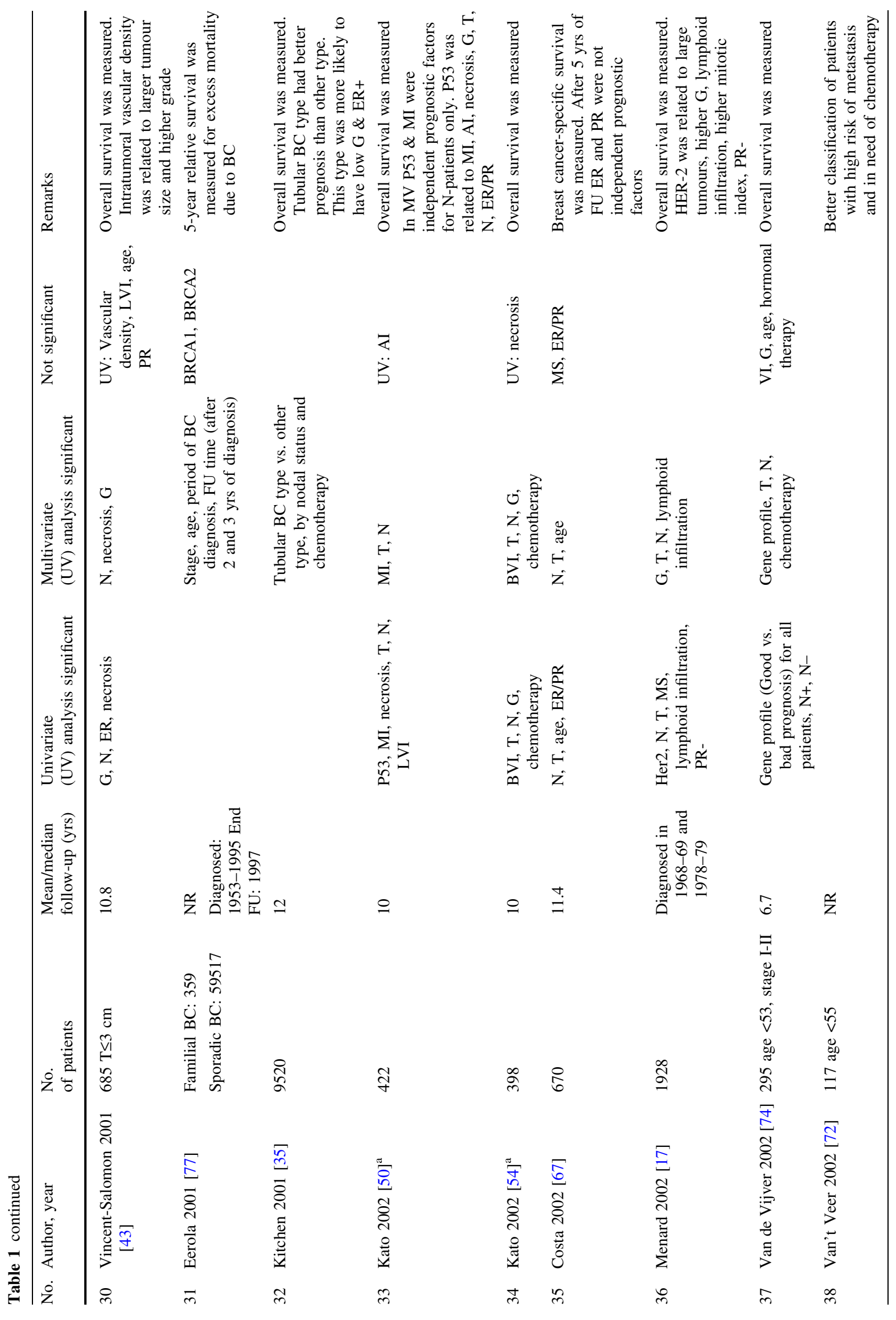




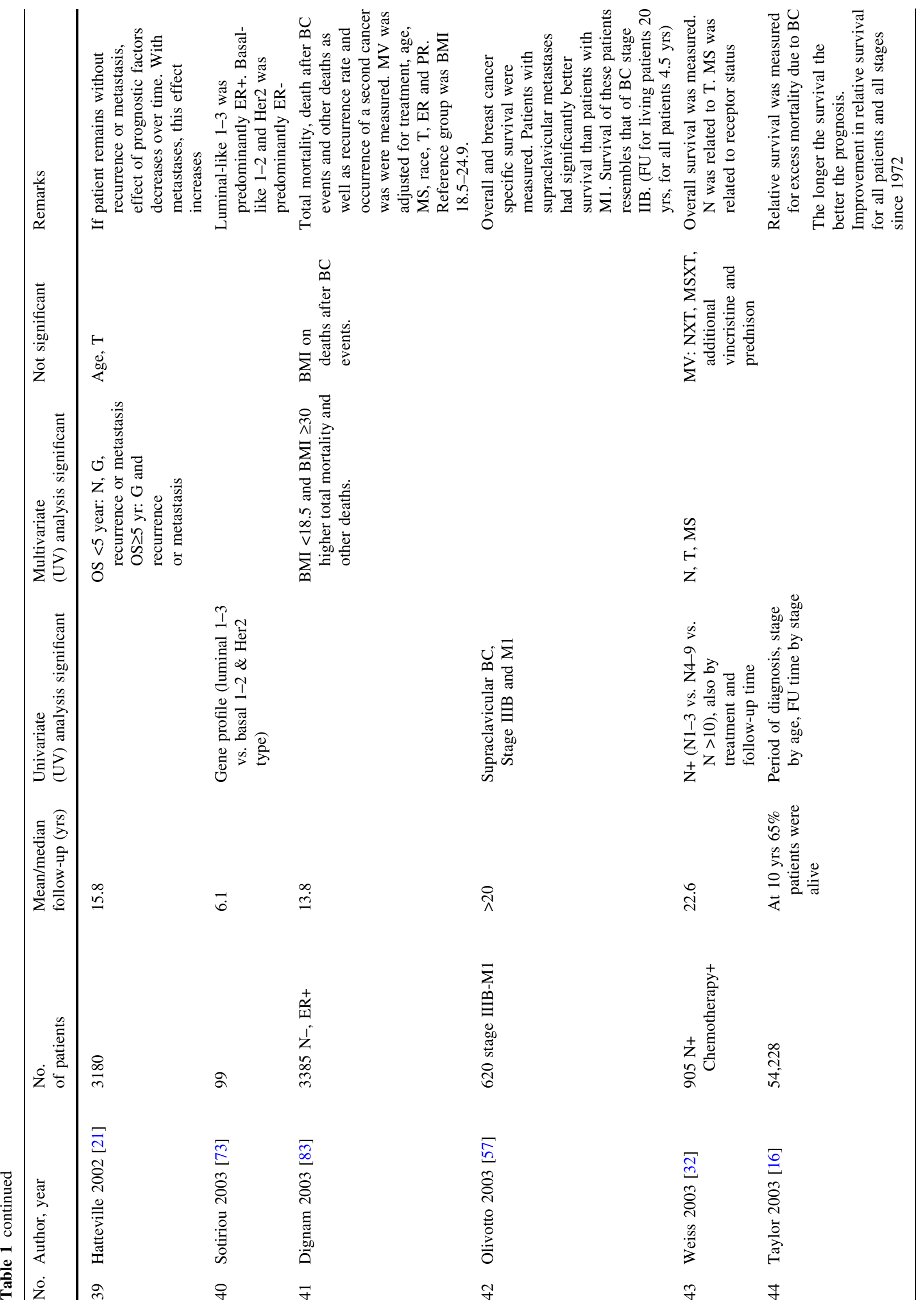




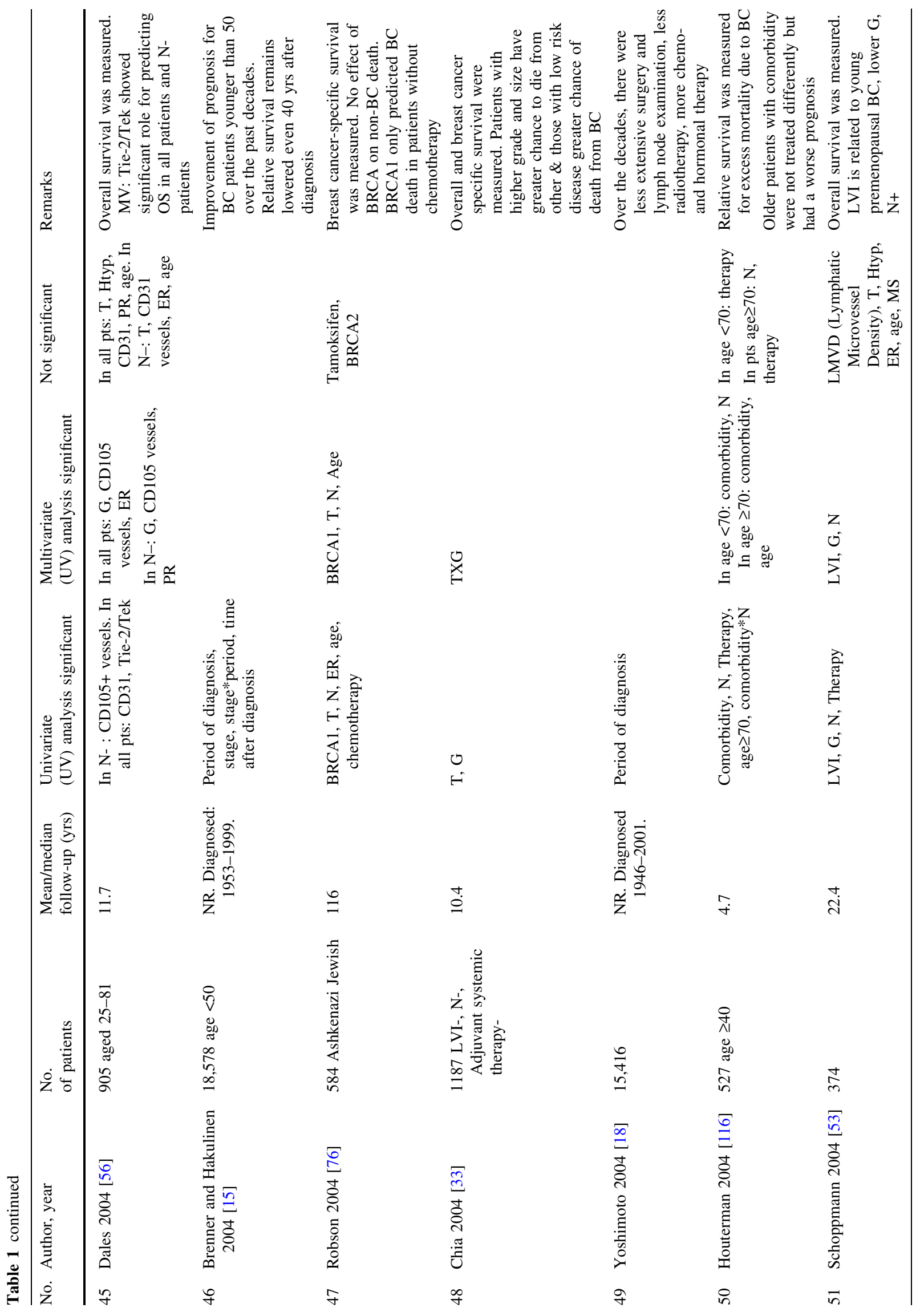




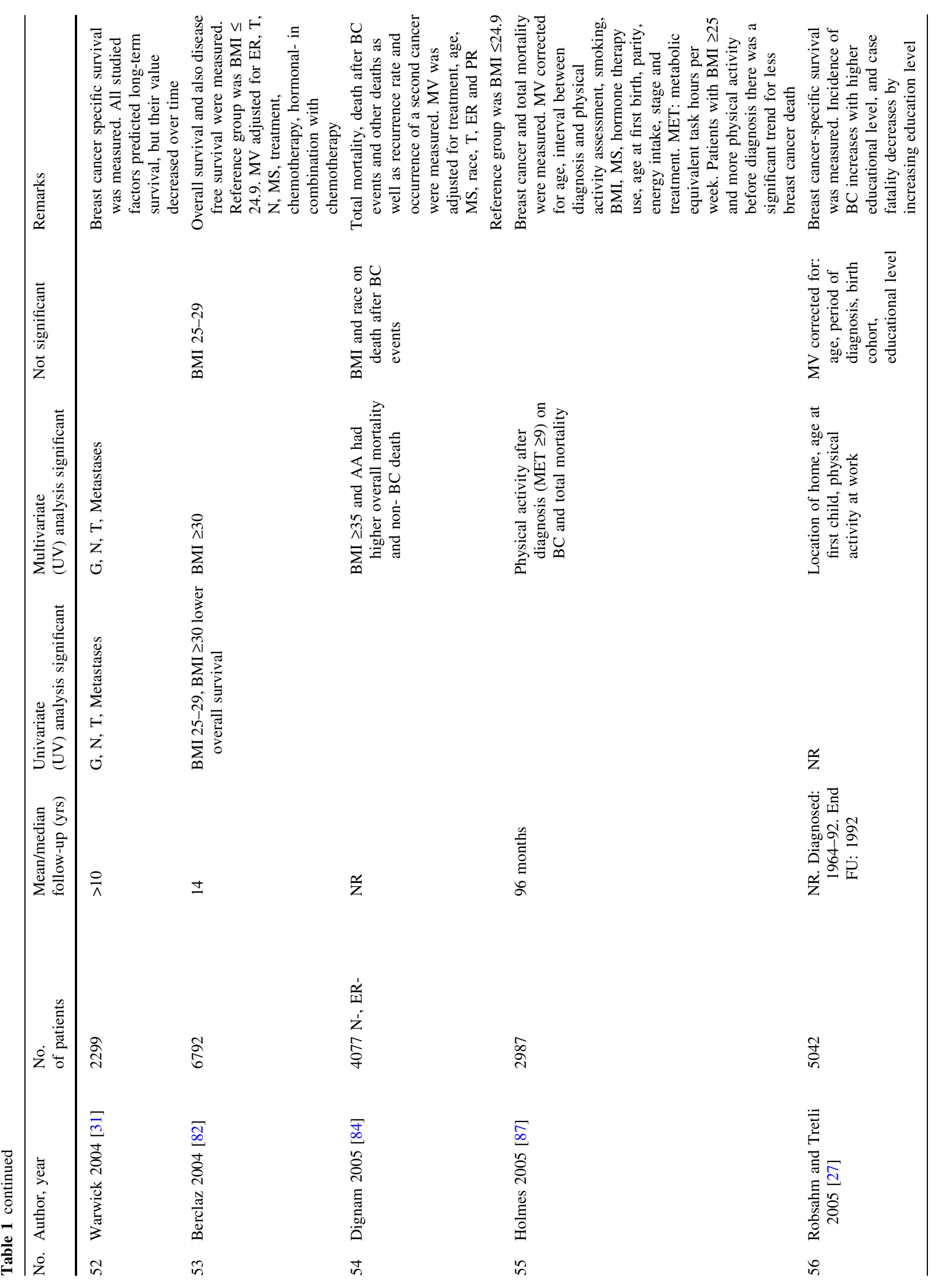




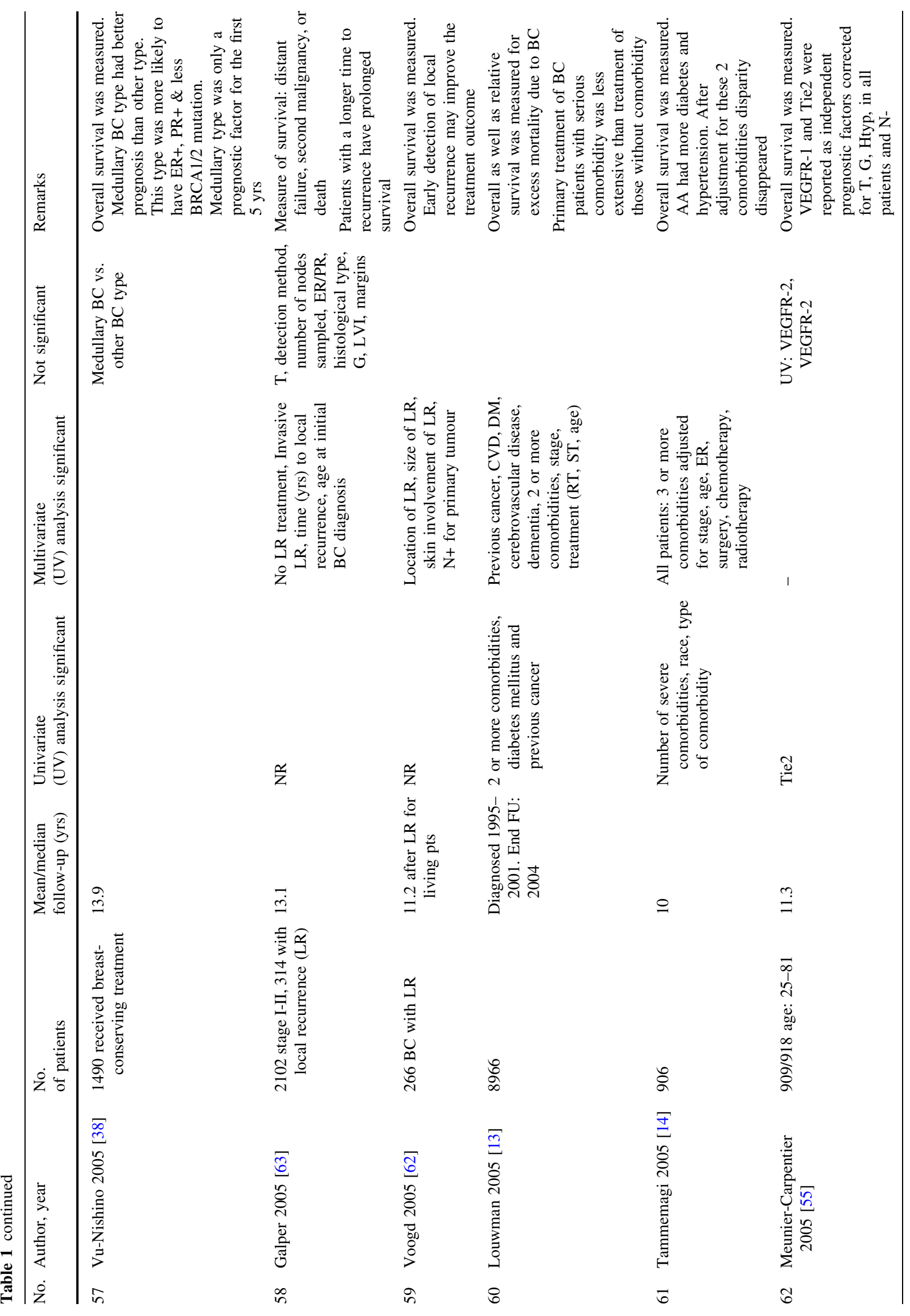




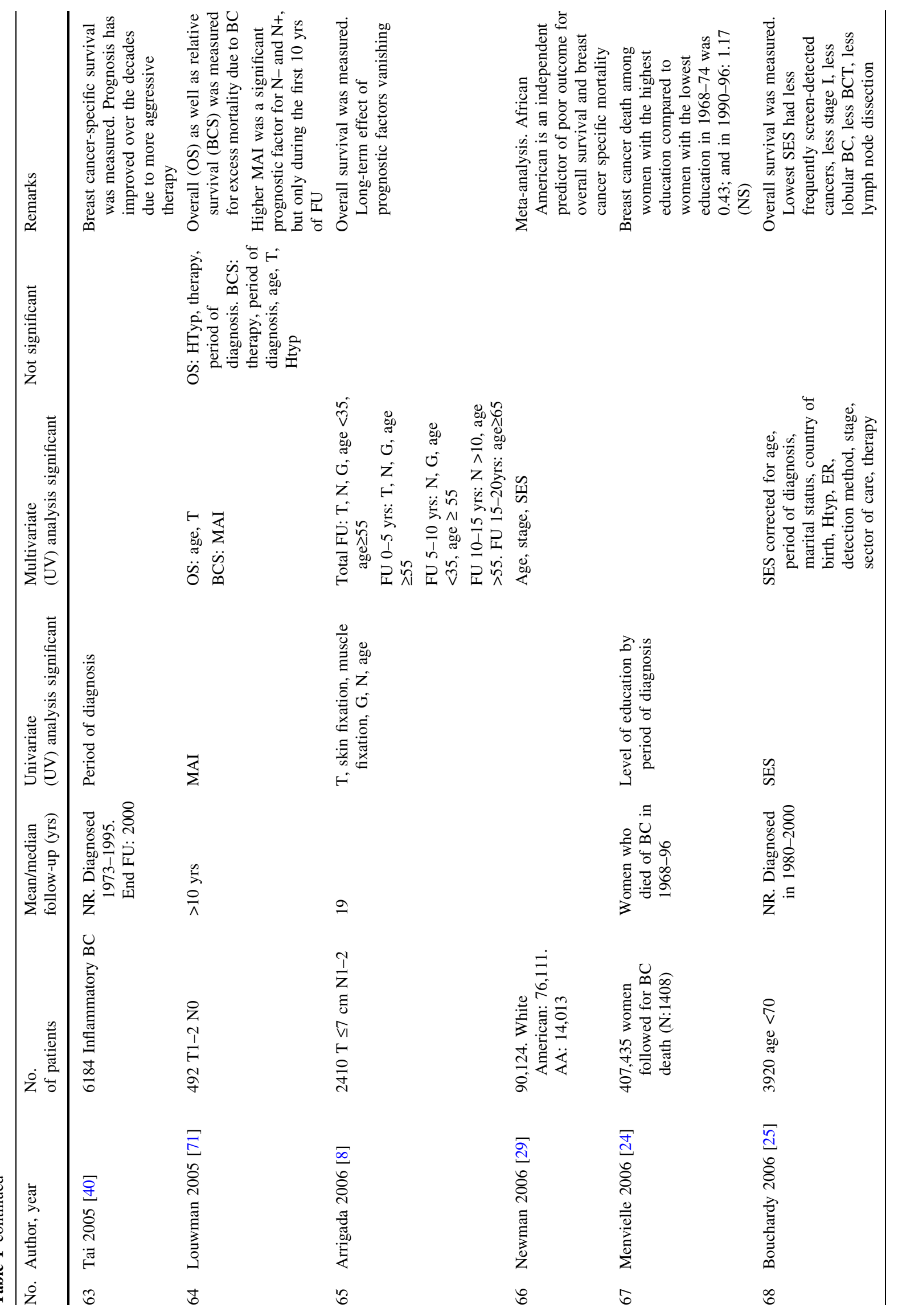




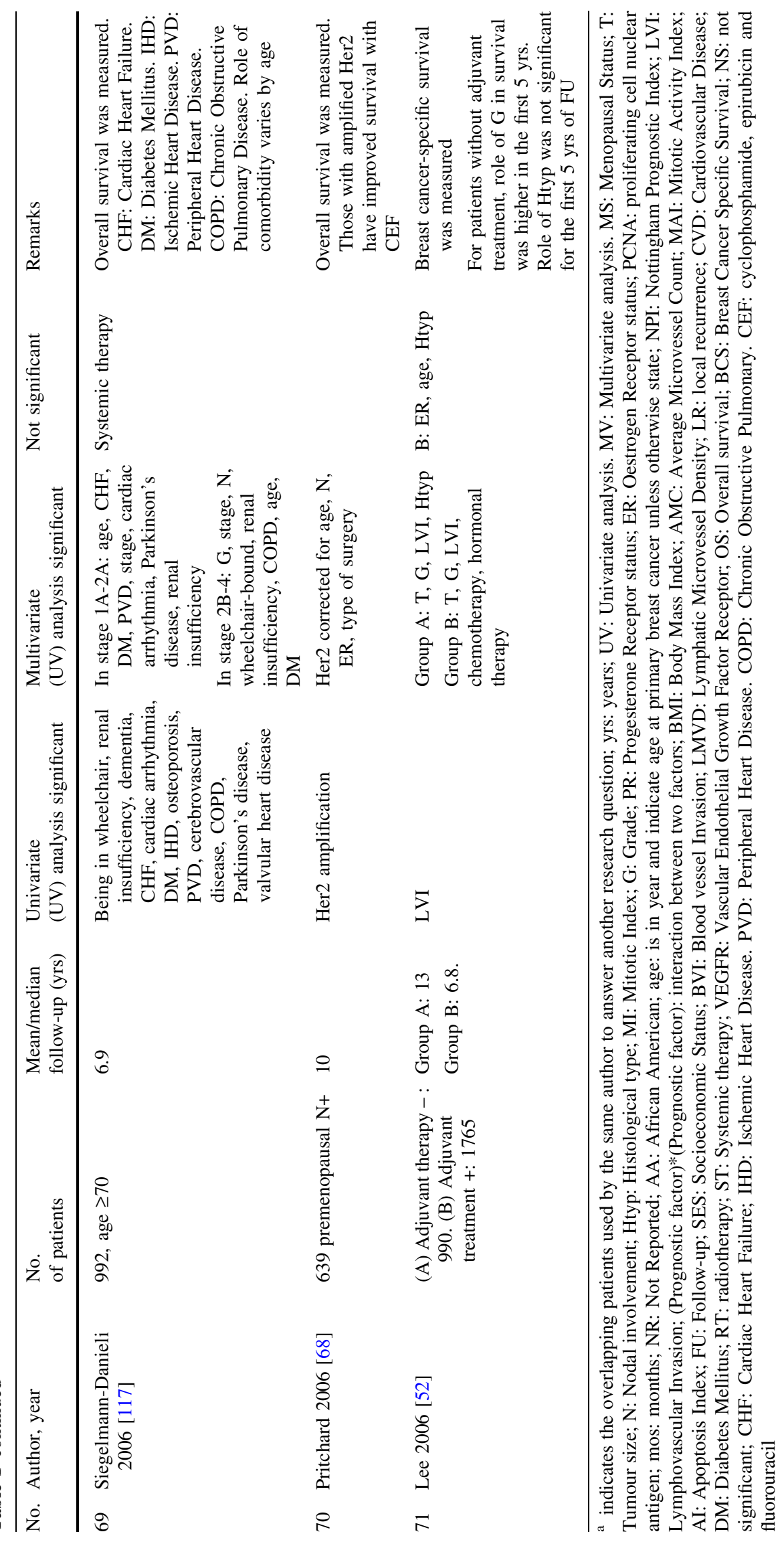




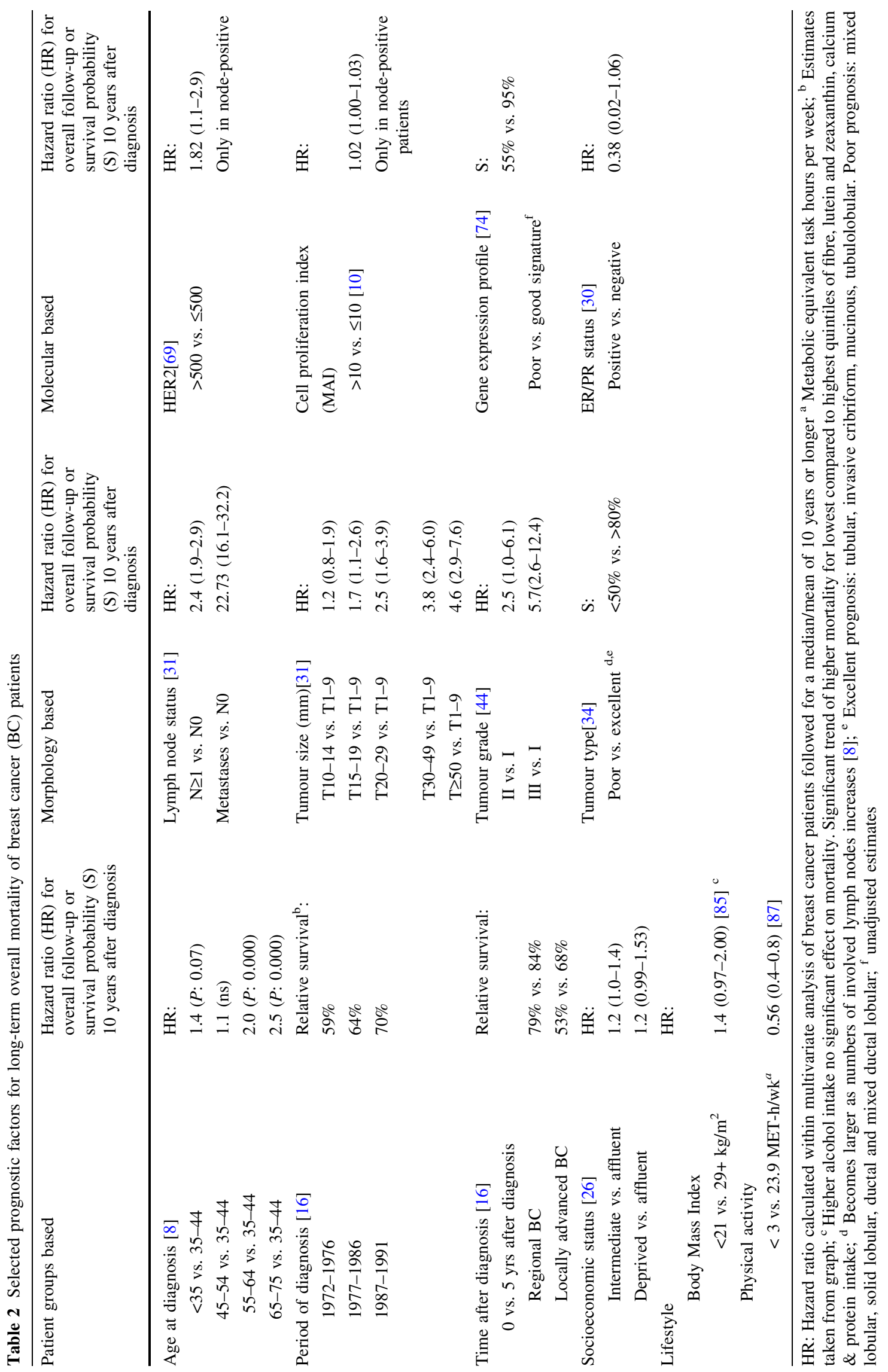


other prognostic factors in determining survival for longterm survivors still needs to be determined.

The role of early detection

Increased awareness among women and improvement in diagnostic procedures have enabled earlier and better detection of $\mathrm{BC}$. Trials on population screening have reported 21-29\% reduction in BC mortality for women invited for screening within 14-16 years of follow-up [19, 97]. Screening identified tumours at an early stage consequently, survival improved [98, 99]. Screening also identified patients with slowly growing tumours who might receive unnecessarily aggressive cancer treatment. Thus, Joensuu et al. [100] examined recurrence rates among patients detected by screening compared to those detected outside screening. After adjusting for tumour aggressiveness (tumour size, nodal status, grade, age, treatment, PR status, HER-2), hence eliminating bias towards detection of indolent cancers (length bias), the benefit of screening for the prognosis for BC patients remained evident.[100] This suggests that other factors explain the indolent behaviour of $\mathrm{BC}$ detected by screening. Hence, until this factor is established, detection mode should probably be considered as a prognostic factor and thus be taken into account in patient management.

The role of treatment

Improvement in $\mathrm{BC}$ treatment has undoubtedly also increased the long-term survival of BC patients [101], as reflected by the improved overall survival across all $\mathrm{BC}$ stages [16]. Using historical data from population-based studies in periods when effective treatment was not available, it was estimated that without treatment only $4 \%$ of BC patients would survive 10 years or longer [102]. BC treatment guidelines have been modified continuously in the last 28 years, tailored to most of the prognosticators mentioned earlier [51]. Effectiveness of various treatment modalities has been summarized by others who conclude that radiation, chemotherapy and hormonal therapy may reduce long-term mortality by up to $57 \%$ [66, 103-105]. Emerging new therapeutic approaches using a monoclonal antibody directed against HER-2 have yielded improved short-term survival for advanced stage [106] as well as operable BC patients [107]. Quality of treatment as indicated by loco-regional failure [108], surgeon workload [109] or hospital volume [110], may affect survival although its role on long-term survival still needs confirmation. In conclusion, on the one hand we have observed a shift in stage towards less aggressive cancers; on the other hand, better and more (systemic) treatment has become available, leading to improved survival for BC patients.

\section{Conclusion}

The prognosis of $\mathrm{BC}$ has become relatively good, with current 10 -year relative survival about $70 \%$ in most western populations [16, 111], especially if up-to-date statistical method such as the period analyses is used [111] (Table 1). Even better, the longer patients survive their BC the higher their survival chance [16]. Our review shows conventional prognostic factors of survival, such as tumour size, lymph node status and grade, remain the most important determinants of 10-year survival for BC patients (Table 2). Most studies agreed on the value of MAI and LVI for prediction of long-term survival. The influence of host factors including age, race/ethnicity or socio-economic factors and tumourrelated factors such as histological type and angiogenesis diminishes after correction for other factors. For most recent markers such as Her2, gene profiling, p53 mutation and uPA level longer follow-up is needed. Recurrence, metastases and a second cancer double the burden of disease thus increase risk of mortality. Similarly, co-occurrence with other diseases is in no doubt decrease survival.

Healthier lifestyle generally increases long-term survival. Modifiable risk factors (such as alcohol consumption and obesity) not only affect incidence but also tumour' clinical behaviour and thus survival.

Although a lot is known about the prognosis for $\mathrm{BC}$ patients, effect of traditional prognostic factors appears to attenuate over time, leaving room for studies on the role of other and newer factors for long-term survival.

\section{References}

1. Parkin DM, Bray F, Ferlay J et al (2005) Global cancer statistics, 2002. CA Cancer J Clin 55:74-108

2. Sant M, Aareleid T, Berrino F et al (2003) EUROCARE-3: survival of cancer patients diagnosed 1990-94-results and commentary. Ann Oncol 14(Suppl 5):v61-118

3. Botha JL, Bray F, Sankila R et al (2003) Breast cancer incidence and mortality trends in 16 European countries. Eur J Cancer 39:1718-1729

4. ACS: Cancer facts and figures 2005. Atlanta, 2005

5. Janssen-Heijnen MLG, Louwman WJ, van de Poll-Franse LV et al (2005) Van meten naar weten. 50 jaar kankerregistratie. Integraal Kankercentrum Zuid (IKZ), Eindhoven, 104 pp

6. Kroman N, Jensen MB, Wohlfahrt J et al (2000) Factors influencing the effect of age on prognosis in breast cancer: population based study. BMJ 320:474-478

7. Aebi S, Gelber S, Castiglione-Gertsch M et al (2000) Is chemotherapy alone adequate for young women with oestrogenreceptor-positive breast cancer? Lancet 355:1869-1874

8. Arriagada R, Le MG, Dunant A et al (2006) Twenty-five years of follow-up in patients with operable breast carcinoma: correlation between clinicopathologic factors and the risk of death in each 5-year period. Cancer 106:743-750

9. Fisher ER, Anderson S, Tan-Chiu E et al (2001) Fifteen-year prognostic discriminants for invasive breast carcinoma: National 
Surgical Adjuvant Breast and Bowel Project Protocol-06. Cancer 91:1679-1687

10. Pietilainen T, Lipponen P, Aaltomaa S et al (1995) Expression of p53 protein has no independent prognostic value in breast cancer. J Pathol 177:225-232

11. Kollias J, Elston CW, Ellis IO et al (1997) Early-onset breast cancer-histopathological and prognostic considerations. Br J Cancer 75:1318-1323

12. West DW, Satariano WA, Ragland DR et al (1996) Comorbidity and breast cancer survival: a comparison between black and white women. Ann Epidemiol 6:413-419

13. Louwman WJ, Janssen-Heijnen ML, Houterman S et al (2005) Less extensive treatment and inferior prognosis for breast cancer patient with comorbidity: a population-based study. Eur J Cancer 41:779-785

14. Tammemagi CM, Nerenz D, Neslund-Dudas C et al (2005) Comorbidity and survival disparities among black and white patients with breast cancer. JAMA 294:1765-1772

15. Brenner H, Hakulinen T (2004) Are patients diagnosed with breast cancer before age 50 years ever cured? J Clin Oncol 22:432-438

16. Taylor R, Davis P, Boyages J (2003) Long-term survival of women with breast cancer in New South Wales. Eur J Cancer 39:215-222

17. Menard S, Balsari A, Casalini $P$ et al (2002) HER-2-positive breast carcinomas as a particular subset with peculiar clinical behaviors. Clin Cancer Res 8:520-525

18. Yoshimoto M, Tada K, Hori $\mathrm{H}$ et al (2004) Improvement in the prognosis of Japanese breast cancer patients from 1946 to 2001-an institutional review. Jpn J Clin Oncol 34:457-462

19. Nystrom L, Andersson I, Bjurstam N et al (2002) Long-term effects of mammography screening: updated overview of the Swedish randomised trials. Lancet 359:909-919

20. Otto SJ, Fracheboud J, Looman CW et al (2003) Initiation of population-based mammography screening in Dutch municipalities and effect on breast-cancer mortality: a systematic review. Lancet 361:1411-1417

21. Hatteville L, Mahe C, Hill C (2002) Prediction of the long-term survival in breast cancer patients according to the present oncological status. Stat Med 21:2345-2354

22. Brenner H, Gefeller O, Hakulinen T (2004) Period analysis for 'up-to-date' cancer survival data: theory, empirical evaluation, computational realisation and applications. Eur $\mathrm{J}$ Cancer 40:326-335

23. Hooning MJ, Aleman BM, van Rosmalen AJ et al (2006) Causespecific mortality in long-term survivors of breast cancer: a 25year follow-up study. Int J Radiat Oncol Biol Phys 64:10811091

24. Menvielle G, Leclerc A, Chastang JF et al (2006) Social inequalities in breast cancer mortality among French women: disappearing educational disparities from 1968 to 1996 . Br J Cancer 94:152-155

25. Bouchardy C, Verkooijen HM, Fioretta G (2006) Social class is an important and independent prognostic factor of breast cancer mortality. Int J Cancer 119(5):1145-1151

26. Thomson CS, Hole DJ, Twelves CJ et al (2001) Prognostic factors in women with breast cancer: distribution by socioeconomic status and effect on differences in survival. J Epidemiol Community Health 55:308-315

27. Robsahm TE, Tretli S (2005) Weak associations between sociodemographic factors and breast cancer: possible effects of early detection. Eur J Cancer Prev 14:7-12

28. Wojcik BE, Spinks MK, Optenberg SA (1998) Breast carcinoma survival analysis for African American and white women in an equal-access health care system. Cancer 82:1310-1218
29. Newman LA, Griffith KA, Jatoi I et al (2006) Meta-analysis of survival in African American and white American patients with breast cancer: ethnicity compared with socioeconomic status. J Clin Oncol 24:1342-1349

30. Vorgias G, Koukouras D, Paleogianni V et al (2001) Prognostic significance of factors affecting disease free interval and overall survival for Stage II breast cancer in Greece. A multivariate cohort study. Eur J Obstet Gynecol Reprod Biol 95:100-104

31. Warwick J, Tabar L, Vitak B et al (2004) Time-dependent effects on survival in breast carcinoma: results of 20 years of follow-up from the Swedish Two-County Study. Cancer 100:1331-1336

32. Weiss RB, Woolf SH, Demakos E et al (2003) Natural history of more than 20 years of node-positive primary breast carcinoma treated with cyclophosphamide, methotrexate, and fluorouracilbased adjuvant chemotherapy: a study by the Cancer and Leukemia Group B. J Clin Oncol 21:1825-1835

33. Chia SK, Speers CH, Bryce CJ et al (2004) Ten-year outcomes in a population-based cohort of node-negative, lymphatic, and vascular invasion-negative early breast cancers without adjuvant systemic therapies. J Clin Oncol 22:1630-1637

34. Galea MH, Blamey RW, Elston CE et al (1992) The Nottingham Prognostic Index in primary breast cancer. Breast Cancer Res Treat 22:207-219

35. Kitchen PR, Smith TH, Henderson MA et al (2001) Tubular carcinoma of the breast: prognosis and response to adjuvant systemic therapy. ANZ J Surg 71:27-31

36. Northridge ME, Rhoads GG, Wartenberg D et al (1997) The importance of histologic type on breast cancer survival. J Clin Epidemiol 50:283-290

37. Reed W, Hannisdal E, Boehler PJ et al (2000) The prognostic value of p53 and c-erb B-2 immunostaining is overrated for patients with lymph node negative breast carcinoma: a multivariate analysis of prognostic factors in 613 patients with a follow-up of 14-30 years. Cancer 88:804-813

38. Vu-Nishino H, Tavassoli FA, Ahrens WA et al (2005) Clinicopathologic features and long-term outcome of patients with medullary breast carcinoma managed with breast-conserving therapy (BCT). Int J Radiat Oncol Biol Phys 62:1040-1047

39. Gamel JW, Meyer JS, Feuer E et al (1996) The impact of stage and histology on the long-term clinical course of 163,808 patients with breast carcinoma. Cancer 77:1459-1464

40. Tai P, Yu E, Shiels R et al (2005) Short- and long-term causespecific survival of patients with inflammatory breast cancer. BMC Cancer 5:137

41. Harris JR, Lippman ME, Morrow M et al (2004) Diseases of the breast 3rd edn. Philadelphia, Lippincott Williams \& Wilkins

42. Gilchrist KW, Kalish L, Gould VE et al (1985) Interobserver reproducibility of histopathological features in stage II breast cancer. An ECOG study. Breast Cancer Res Treat 5:3-10

43. Vincent-Salomon A, Carton M, Zafrani B et al (2001) Long term outcome of small size invasive breast carcinomas independent from angiogenesis in a series of 685 cases. Cancer 92:249-256

44. Kato T, Kameoka S, Kimura T et al (2001) Angiogenesis as a predictor of long-term survival for 377 Japanese patients with breast cancer. Breast Cancer Res Treat 70:65-74

45. Tabar L, Duffy SW, Vitak B et al (1999) The natural history of breast carcinoma: what have we learned from screening? Cancer $86: 449-462$

46. Kollias J, Murphy CA, Elston CW et al (1999) The prognosis of small primary breast cancers. Eur J Cancer 35:908-912

47. Pinder SE, Murray S, Ellis IO et al (1998) The importance of the histologic grade of invasive breast carcinoma and response to chemotherapy. Cancer 83:1529-1539 
48. Frkovic-Grazio S, Bracko M (2002) Long term prognostic value of Nottingham histological grade and its components in early (pT1N0M0) breast carcinoma. J Clin Pathol 55:88-92

49. D'Eredita G, Giardina C, Martellotta M et al (2001) Prognostic factors in breast cancer: the predictive value of the Nottingham Prognostic Index in patients with a long-term follow-up that were treated in a single institution. Eur J Cancer 37:591-596

50. Kato T, Kameoka S, Kimura $\mathrm{T}$ et al (2002) p53, mitosis, apoptosis and necrosis as prognostic indicators of long-term survival in breast cancer. Anticancer Res 22:1105-1112

51. Goldhirsch A, Glick JH, Gelber RD et al (2005) Meeting highlights: international expert consensus on the primary therapy of early breast cancer 2005. Ann Oncol 16:1569-1583

52. Lee AH, Pinder SE, Macmillan RD et al (2006) Prognostic value of lymphovascular invasion in women with lymph node negative invasive breast carcinoma. Eur J Cancer 42:357-362

53. Schoppmann SF, Bayer G, Aumayr K et al (2004) Prognostic value of lymphangiogenesis and lymphovascular invasion in invasive breast cancer. Ann Surg 240:306-312

54. Kato T, Kameoka S, Kimura T et al (2002) Blood vessel invasion as a predictor of long-term survival for Japanese patients with breast cancer. Breast Cancer Res Treat 73:1-12

55. Meunier-Carpentier S, Dales JP, Djemli A et al (2005) Comparison of the prognosis indication of VEGFR-1 and VEGFR-2 and $\mathrm{Tie} 2$ receptor expression in breast carcinoma. Int $\mathrm{J}$ Oncol 26:977-984

56. . Dales JP, Garcia S, Carpentier S et al (2004) Long-term prognostic significance of neoangiogenesis in breast carcinomas: comparison of Tie-2/Tek, CD105, and CD31 immunocytochemical expression. Hum Pathol 35:176-183

57. Olivotto IA, Chua B, Allan SJ et al (2003) Long-term survival of patients with supraclavicular metastases at diagnosis of breast cancer. J Clin Oncol 21:851-854

58. Nomura Y, Tsutsui S, Murakami S et al (1999) Prognostic impact of second cancer on the survival of early breast cancer patients. Int J Oncol 14:1103-1109

59. Raymond JS, Hogue CJ (2006) Multiple primary tumours in women following breast cancer, 1973-2000. Br J Cancer 94:1745-1750

60. Kollias J, Ellis IO, Elston CW et al (2001) Prognostic significance of synchronous and metachronous bilateral breast cancer. World J Surg 25:1117-1124

61. Wapnir IL, Anderson SJ, Mamounas EP et al (2006) Prognosis after ipsilateral breast tumor recurrence and locoregional recurrences in five National Surgical Adjuvant Breast and Bowel Project node-positive adjuvant breast cancer trials. J Clin Oncol 24:2028-2037

62. Voogd AC, van Oost FJ, Rutgers EJ et al (2005) Long-term prognosis of patients with local recurrence after conservative surgery and radiotherapy for early breast cancer. Eur J Cancer 41:2637-2344

63. Galper S, Blood E, Gelman R et al (2005) Prognosis after local recurrence after conservative surgery and radiation for earlystage breast cancer. Int J Radiat Oncol Biol Phys 61:348-357

64. Habel LA, Shak S, Jacobs MK et al (2006) A population-based study of tumor gene expression and risk of breast cancer death among lymph node-negative patients. Breast Cancer Res 8:R25

65. Obedian E, Fischer DB, Haffty BG (2000) Second malignancies after treatment of early-stage breast cancer: lumpectomy and radiation therapy versus mastectomy. J Clin Oncol 18: 2406-2412

66. Early Breast Cancer Trialists' Collaborative Group (2005) Effects of chemotherapy and hormonal therapy for early breast cancer on recurrence and 15-year survival: an overview of the randomised trials. Lancet 365:1687-1717
67. Costa SD, Lange S, Klinga K et al (2002) Factors influencing the prognostic role of oestrogen and progesterone receptor levels in breast cancer-results of the analysis of 670 patients with 11 years of follow-up. Eur J Cancer 38:1329-1334

68. Pritchard KI, Shepherd LE, O'Malley FP et al (2006) HER2 and responsiveness of breast cancer to adjuvant chemotherapy. N Engl J Med 354:2103-2111

69. Ferrero-Pous M, Hacene K, Bouchet C et al (2000) Relationship between c-erbB-2 and other tumor characteristics in breast cancer prognosis. Clin Cancer Res 6:4745-4754

70. Haerslev T, Jacobsen GK, Zedeler K (1995) Proliferating cell nuclear antigen (PCNA) and c-erbB-2 oncoprotein in breast carcinoma with correlations to histopathological parameters and prognosis. Oncol Rep 2:99-105

71. Louwman WJ, van Beek MW, Schapers RF et al (2005) Longterm survival of $\mathrm{T} 1$ and $\mathrm{T} 2$ lymph node-negative breast cancer patients according to mitotic activity index: a population-based study. Int J Cancer 118(9):2310-2314

72. van 't Veer LJ, Dai H, van de Vijver MJ et al (2002) Gene expression profiling predicts clinical outcome of breast cancer. Nature 415:530-536

73. Sotiriou C, Neo SY, McShane LM et al (2003) Breast cancer classification and prognosis based on gene expression profiles from a population-based study. Proc Natl Acad Sci USA 100:10393-10398

74. van de Vijver MJ, He YD, van't Veer LJ et al (2002) A geneexpression signature as a predictor of survival in breast cancer. N Engl J Med 347:1999-2009

75. Miki Y, Swensen J, Shattuck-Eidens D et al (1994) A strong candidate for the breast and ovarian cancer susceptibility gene BRCA1. Science 266:66-71

76. Robson ME, Chappuis PO, Satagopan J et al (2004) A combined analysis of outcome following breast cancer: differences in survival based on BRCA1/BRCA2 mutation status and administration of adjuvant treatment. Breast Cancer Res 6:R8-R17

77. Eerola H, Vahteristo P, Sarantaus L et al (2001) Survival of breast cancer patients in BRCA1, BRCA2, and non-BRCA1/2 breast cancer families: a relative survival analysis from Finland. Int J Cancer 93:368-372

78. Ferrero JM, Ramaioli A, Formento JL et al (2000) P53 determination alongside classical prognostic factors in node-negative breast cancer: an evaluation at more than 10-year follow-up. Ann Oncol 11:393-397

79. Haerslev T, Jacobsen GK (1995) An immunohistochemical study of $\mathrm{p} 53$ with correlations to histopathological parameters, c-erbB-2, proliferating cell nuclear antigen, and prognosis. Hum Pathol 26:295-301

80. Mirza AN, Mirza NQ, Vlastos G et al (2002) Prognostic factors in node-negative breast cancer: a review of studies with sample size more than 200 and follow-up more than 5 years. Ann Surg 235:10-26

81. Fitzgibbons PL, Page DL, Weaver D et al (2000) Prognostic factors in breast cancer. College of American Pathologists Consensus Statement 1999. Arch Pathol Lab Med 124:966-78

82. Berclaz G, Li S, Price KN et al (2004) Body mass index as a prognostic feature in operable breast cancer: the International Breast Cancer Study Group experience. Ann Oncol 15:875884

83. Dignam JJ, Wieand K, Johnson KA et al (2003) Obesity, tamoxifen use, and outcomes in women with estrogen receptorpositive early-stage breast cancer. J Natl Cancer Inst 95:14671476

84. Dignam JJ, Wieand K, Johnson KA et al (2006) Effects of obesity and race on prognosis in lymph node-negative, estrogen 
receptor-negative breast cancer. Breast Cancer Res Treat 97(3):245-254

85. Holmes MD, Stampfer MJ, Colditz GA et al (1999) Dietary factors and the survival of women with breast carcinoma. Cancer 86:826-835

86. Byers T, Sedjo RL (2006) A weight loss trial for breast cancer recurrence: pre-menopausal, post-menopausal, both, or neither? Cancer Causes Control 17:1-3

87. Holmes MD, Chen WY, Feskanich D et al (2005) Physical activity and survival after breast cancer diagnosis. JAMA 293:2479-2486

88. Brown JK, Byers T, Doyle C et al (2003) Nutrition and physical activity during and after cancer treatment: an American Cancer Society guide for informed choices. CA Cancer J Clin 53:268-291

89. Kroenke CH, Fung TT, Hu FB et al (2005) Dietary patterns and survival after breast cancer diagnosis. J Clin Oncol 23:9295-9303

90. Colditz GA (2005) Estrogen, estrogen plus progestin therapy, and risk of breast cancer. Clin Cancer Res 11:909s-917s

91. Garcia-Closas M, Brinton LA, Lissowska J et al (2006) Established breast cancer risk factors by clinically important tumour characteristics. Br J Cancer 95:123-129

92. Suzuki R, Rylander-Rudqvist T, Ye W et al (2006) Body weight and postmenopausal breast cancer risk defined by estrogen and progesterone receptor status among Swedish women: a prospective cohort study. Int J Cancer 119:1683-1689

93. Suzuki R, Ye W, Rylander-Rudqvist T et al (2005) Alcohol and postmenopausal breast cancer risk defined by estrogen and progesterone receptor status: a prospective cohort study. J Natl Cancer Inst 97:1601-1608

94. Takeuchi H, Baba H, Kano T et al (2005) The time-related changes of the importance of prognostic factors in breast cancer. A sequential multivariate analysis of 1423 Japanese patients. Breast Cancer Res Treat 94:273-278

95. Zahl PH, Tretli S (1997) Long-term survival of breast cancer in Norway by age and clinical stage. Stat Med 16:1435-1449

96. Liu S, Edgerton SM, Moore DH 2nd et al (2001) Measures of cell turnover (proliferation and apoptosis) and their association with survival in breast cancer. Clin Cancer Res 7:1716-1723

97. Alexander FE, Anderson TJ, Brown HK et al (1999) 14 years of follow-up from the Edinburgh randomised trial of breast-cancer screening. Lancet 353:1903-1908

98. Tabar L, Yen MF, Vitak B et al (2003) Mammography service screening and mortality in breast cancer patients: 20-year follow-up before and after introduction of screening. Lancet 361:1405-1410

99. Shen Y, Yang Y, Inoue LY et al (2005) Role of detection method in predicting breast cancer survival: analysis of randomized screening trials. J Natl Cancer Inst 97:1195-1203

100. Joensuu H, Lehtimaki T, Holli K et al (2004) Risk for distant recurrence of breast cancer detected by mammography screening or other methods. JAMA 292:1064-1073

101. Peto R, Boreham J, Clarke M et al (2000) UK and USA breast cancer deaths down $25 \%$ in year 2000 at ages 20-69 years. Lancet 355:1822

102. Johnstone PA, Norton MS, Riffenburgh RH (2000) Survival of patients with untreated breast cancer. J Surg Oncol 73:273-277
103. Fisher B, Jeong JH, Bryant J et al (2004) Treatment of lymphnode-negative, oestrogen-receptor-positive breast cancer: long-term findings from National Surgical Adjuvant Breast and Bowel Project randomised clinical trials. Lancet 364:858-868

104. Clarke M, Collins R, Darby S et al (2005) Effects of radiotherapy and of differences in the extent of surgery for early breast cancer on local recurrence and 15-year survival: an overview of the randomised trials. Lancet 366:2087-2106

105. Fisher B, Jeong JH, Anderson S et al (2004) Treatment of axillary lymph node-negative, estrogen receptor-negative breast cancer: updated findings from National Surgical Adjuvant Breast and Bowel Project clinical trials. J Natl Cancer Inst 96:1823-1831

106. Hurley J, Doliny P, Reis I et al (2006) Docetaxel, cisplatin, and trastuzumab as primary systemic therapy for human epidermal growth factor receptor 2-positive locally advanced breast cancer. J Clin Oncol 24:1831-1838

107. Romond EH, Perez EA, Bryant J et al (2005) Trastuzumab plus adjuvant chemotherapy for operable HER2-positive breast cancer. N Engl J Med 353:1673-1684

108. Ernst MF, Voogd AC, Coebergh JW et al (2004) Using locoregional recurrence as an indicator of the quality of breast cancer treatment. Eur J Cancer 40:487-493

109. Stefoski Mikeljevic J, Haward RA, Johnston C et al (2003) Surgeon workload and survival from breast cancer. Br J Cancer 89:487-491

110. Simunovic M, Rempel E, Theriault ME et al (2006) Influence of hospital characteristics on operative death and survival of patients after major cancer surgery in Ontario. Can J Surg 49:251-258

111. Houterman S, Janssen-Heijnen ML, van de Poll-Franse LV et al (2006) Higher long-term cancer survival rates in southeastern Netherlands using up-to-date period analysis. Ann Oncol 17(4):709-712

112. Haerslev T, Jacobsen GK, Zedeler K (1996) Correlation of growth fraction by $\mathrm{Ki}-67$ and proliferating cell nuclear antigen (PCNA) immunohistochemistry with histopathological parameters and prognosis in primary breast carcinomas. Breast Cancer Res Treat 37:101-113

113. Gaffney DK, Brohet RM, Lewis CM et al (1998) Response to radiation therapy and prognosis in breast cancer patients with BRCA1 and BRCA2 mutations. Radiother Oncol 47:129-136

114. Mansi JL, Gogas H, Bliss JM et al (1999) Outcome of primarybreast-cancer patients with micrometastases: a long-term followup study. Lancet 354:197-202

115. Page DL, Gray R, Allred DC et al (2001) Prediction of nodenegative breast cancer outcome by histologic grading and S-phase analysis by flow cytometry: an Eastern Cooperative Oncology Group Study (2192). Am J Clin Oncol 24:10-18

116. Houterman S, Janssen-Heijnen ML, Verheij CD et al (2004) Comorbidity has negligible impact on treatment and complications but influences survival in breast cancer patients. $\mathrm{Br} \mathrm{J}$ Cancer 90:2332-2337

117. Siegelmann-Danieli N, Khandelwal V, Wood GC et al (2006) Breast cancer in elderly women: outcome as affected by age, tumor features, comorbidities, and treatment approach. Clin Breast Cancer 7:59-66 